\title{
Revised concept of the fossil genus Oviparosiphum Shaposhnikov, 1979 with the description of a new genus (Hemiptera, Sternorrhyncha, Aphidomorpha)
}

\author{
Dagmara Żyła', Agnieszka Homan², Barbara Franielczyk², Piotr Wegierek² \\ I Department of Natural History, Upper Silesian Museum, Plac Jana III Sobieskiego 2, 41-902 Bytom, Poland \\ 2 Department of Zoology, University of Silesia, Bankowa 9, 40-007 Katowice, Poland \\ Corresponding author: Dagmara Żyła (zyladagmara@gmail.com)
}

Academic editor: R. Blackman | Received 6 November 2014 | Accepted 9 February 2015 | Published 19 February 2015

http://zoobank.org/CB36F3AA-C7E0-47D1-B38F-E3CBOA046DBA

Citation: Żyła D, Homan A, Franielczyk B, Wegierek P (2015) Revised concept of the fossil genus Oviparosiphum Shaposhnikov, 1979 with the description of a new genus (Hemiptera, Sternorrhyncha, Aphidomorpha). ZooKeys 483: 9-22. doi: 10.3897/zookeys.483.8902

\begin{abstract}
This paper presents a revision of the aphid genus Oviparosiphum, which is known from the Cretaceous period. Redescriptions of two species: O. jakovlevi Shaposhnikov, 1979 and O. baissense Shaposhnikov \& Wegierek, 1989 are made, and an updated diagnosis of this genus is provided. Oviparosiphum baissense is the type species of a newly described genus Archeoviparosiphum gen. n. Five other species of Oviparosiphum are also transferred to the new genus. The basis for their separation from Oviparosiphum is the structure of the siphunculi and ovipositor. A key is provided to the genera of Oviparosiphidae.
\end{abstract}

\section{Keywords}

Aphids, fossils, Cretaceous, Oviparosiphidae, Archeoviparosiphum gen. n., morphology

\section{Introduction}

One aphid family known only from fossils is Oviparosiphidae. Representatives of this family are known from several localities (China, Germany, Mongolia, Russia) but originated within a relatively short time span, from the Early/Middle Jurassic to the end of the Early Cretaceous. The oldest genus is Grimmenaphis Ansorge, 1996, described 
from the Lower Jurassic deposit of Grimmen (Germany). However, it is known only from an isolated wing (Ansorge 1996). The oldest undoubted representative is Khotontaphis Shaposhnikov \& Wegierek, 1989 from the Upper Jurassic/Lower Cretaceous Khotont deposit (Mongolia). More Oviparosiphidae are known from the Early Cretaceous: Acanthotrichaphis Shaposhnikov \& Wegierek, 1989, Dinaphis Shaposhnikov \& Wegierek, 1989, Expansaphis Hong \& Wang, 1990, Oviparosiphum, Sinoviparosiphum Ren, 1995 and Vitimaphis Shaposhnikov \& Wegierek, 1989, but they are absent from Upper Cretaceous sediments (Heie and Wegierek 2011).

This family is highly diverse morphologically, but the simultaneous occurrence of the ovipositor and siphunculi constitutes its most characteristic feature (Shaposhnikov 1979). The first described aphid with both these structures visible was Oviparosiphum jakovlevi from the Lower Cretaceous Bon-Tsagan deposit (Mongolia), which is the type species of the genus Oviparosiphum (Shaposhnikov 1979). To date, the genus includes seven species. The present paper revises the species originally placed in Oviparosiphum. It also emends its diagnosis and describes a new genus.

\section{Material and methods}

The material consisted of 44 aphid fossil specimens borrowed from the collection of the Institute of Palaeontology, Russian Academy of Sciences in Moscow. The fossils were preserved in the form of two imprints - "obverse" and "reverse", marked as \pm . The material was analyzed using standard palaeoentomological research methods (Rasnitsyn 2002). Specimens were photographed using a Nikon SMZ1500 stereoscopic microscope and a Nikon Eclipse E600 polarized light microscope. Selected body parts were photographed using Philips XL 30 TMP ESEM and Tescan Vega scanning electron microscopes (with the backscattered electron detector (BSE) in the low-vacuum mode) for better analysis of their morphology. Photographs and measurements were made in the NIS-Elements program. The figures are based on the combined drawings of reverse and obverse imprints, while the photographs represent only one imprint. All measurements are given in $\mathrm{mm}$.

The imprints were collected from two localities: Baissa, Russia and Bon-Tsagaan, Mongolia. Both of them are Lower Cretaceous deposits.

\section{Geological settings}

Baissa is one of the richest deposits and most important localities of fossil insects from the Early Cretaceous. More than 10000 specimens of insects have been collected from there (Rasnitsyn and Zherikhin 2002). It is located in the Asian part of Russia, in Transbaikalia, in the Buryat Republic, on the left bank of the Vitim River (Kania and Wegierek 2008). The Baissa deposit belongs to the Zaza Formation of approximately Berriasian age (Rasnitsyn et al. 1998). This lithostratigraphic unit is characteristic of 
the Lower Cretaceous sediments throughout western Transbaikalia. It is built mainly of sandstone, limestone, marl and bituminous shale (Zherikhin et al. 1999).

Bon-Tsagan (= Bon-Tsagaan) is one of the richest Mesozoic insect remains deposits in Mongolia, and one of the best known and richest in the world. Numerous outcrops of mudstone and marls are widely distributed in Central Mongolia, south of the recent Lake Bon-Tsagaan-Nur (Rasnitsyn and Zherikhin 2002). The exact age of the lacustrine sediments of Bon-Tsagaan is estimated at the Early Cretaceous, probably the Aptian. Fossils are well preserved in lacustrine sediments of the lake, which was situated in a mountain valley (Ponomarenko 2013).

\section{Systematic palaeontology}

Key to the genera of the family Oviparosiphidae:

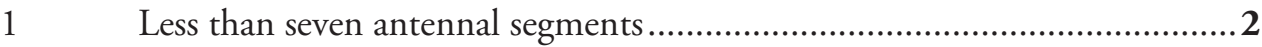

- Seven antennal segments......................................................................... 3

2 Secondary rhinaria round and irregular. Expansaphis Hong \& Wang, 1990

- $\quad$ Secondary rhinaria annular ........................... Sinoviparosiphum Ren, 1995

3 Siphunculi in the form of short truncate cones .......................................... 4

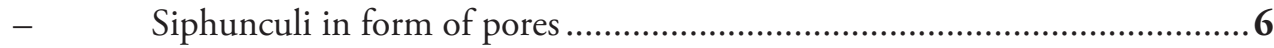

4 Ovipositor large and well-developed .Oviparosiphum Shaposhnikov, 1979

- Ovipositor rudimentary ……….................................................................

5 Cubital veins with separate bases.

Vitimaphis Shaposhnikov \& Wegierek, 1989

- Cubital veins leave the main vein Sc + R + M from one poin........................ Khotontaphis Shaposhnikov \& Wegierek, 1989

$6 \quad$ Vein $\mathrm{CuA}_{1}$ not connected with the main vein $\mathrm{Sc}+\mathrm{R}+\mathrm{M}$

Daoaphis Huang, Wegierek, Żyła \& Nel, 2014

- $\quad$ Vein $\mathrm{CuA}_{1}$ connected with the main vein $\mathrm{Sc}+\mathrm{R}+\mathrm{M}$..............................

$7 \quad$ Pterostigma long, at least 5.5 times longer than wide

Dinaphis Shaposhnikov \& Wegierek, 1989

- $\quad$ Pterostigma short, at most 5 times longer than wide ..................................8 8

8 Abdomen with setae.....Acanthotrichaphis Shaposhnikov \& Wegierek, 1989

- $\quad$ Abdomen without setae. Archeoviparosiphum gen. $\mathbf{n}$.

\section{Genus Oviparosiphum Shaposhnikov, 1979}

Type species. Oviparosiphum jakovlevi Shaposhnikov, 1979

Emended diagnosis. Seven antennal segments. Secondary rhinaria slightly ellipsoidal, large. Siphunculi in the form of short truncate cones. Ovipositor large with valvae I and III well developed. 


\section{Oviparosiphum jakovlevi Shaposhnikov, 1979}

Figs 1, 2, 3, 4

Holotype. 3559/51, Paleontological Institute, Russian Academy of Sciences, Moscow; Bon-Tsagaan locality (Mongolia); Early Cretaceous (Aptian); alate female

Emended diagnosis. As for genus.

Redescription. Body (2.49) thick (Figs 1A-C, 3A). Epicranial suture present (Fig. $4 \mathrm{~A})$, connected in the middle of the epicranium with lateral sutures. On head, narrow oblique slats running from front and lateral edges to the posterior part of the head. Diameter of ocelli 0.05; distance between ocelli 0.24. Segment I of antennae (0.05) shorter than segment II (0.08) (Fig. 4B). Secondary rhinaria arranged in transverse rows (Fig. 2A). Praescutum length 0.37; width 0.52. Femora thick. Fore tibia (1.07) about 2.5 times longer than fore femur (0.38). Length of middle tibia 1.02. Middle tarsus (0.26) (Fig. 2B) about one fourth of middle tibia length. Length of hind coxa 0.11 . Hind tibia (1.18) about twice as long as the hind femur (0.53). Hind tibiae about half the body length. Fore wing (4.76) (Figs 2D, 3B) longer than body length. Base of the wing narrow. Vein surface scaly (Figs 3C, D). Distance from base of wing to end of pterostigma 3.33. Bases of cubital veins very close to each other. $\mathrm{CuA}_{1}(1.46)$ slightly arched distally, separating from main vein at a $45^{\circ}$ angle, slightly shorter than $\mathrm{CuA}_{2}$. Vein $\mathrm{CuA}_{2}$ (1.16) separating from main vein at mid-length between base of the wing and base of vein Rs, at a $70^{\circ}$ angle. Vein $M$ with three branches. Base of vein $M$ directed to base of pterostigma, not connected with main vein. Branches of $\mathrm{M}$ form a wide $\left(50^{\circ}\right)$ fork. Base of fork of $M_{1+2}$ and $M_{3+4}$ behind base of vein Rs. Common stem of vein $M(0.89)$ longer than $M_{1+2}$ length (0.63) and equal to $M_{3+4}$ length. Vein Rs (1.67) slightly curved, leaving proximal part of pterostigma at an angle of $25^{\circ}$ and running close to it. Pterostigma pointed, short and wide; 3 times longer (0.93) than wide (0.31). Hind wing with two cubital vein. Apical part of abdomen slightly sclerotized (Figs 2C, 4C). Basal diameter of siphunculus 0.13 (Fig. 4D). Diameter of siphunculus aperture 0.10 . Ovipositor with valvae I and III well preserved (Fig. 4E). Tergite IX of abdomen clearly visible. Subgenital plate wider than base of ovipositor, 5 times wider than long. In the middle part, its anterior edge forms an indentation reaching half of the length of the plate.

\section{Genus Archeoviparosiphum gen. n.}

http://zoobank.org/B46E2C8B-351B-4392-ADA9-E786234AB825

Type species. Archeoviparosiphum baissense (Shaposhnikov \& Wegierek, 1989), comb. n.

Diagnosis. Seven antennal segments. Secondary rhinaria slightly ellipsoidal, smaller than secondary rhinaria of Oviparosiphum. Vein $\mathrm{CuA}_{1}$ connected with the main vein $\mathrm{Sc}+\mathrm{R}+\mathrm{M}$. Pterostigma short, at most 5 times longer than wide. Abdomen without setae. Siphunculi in form of pores. Ovipositor small and rudimentary. 

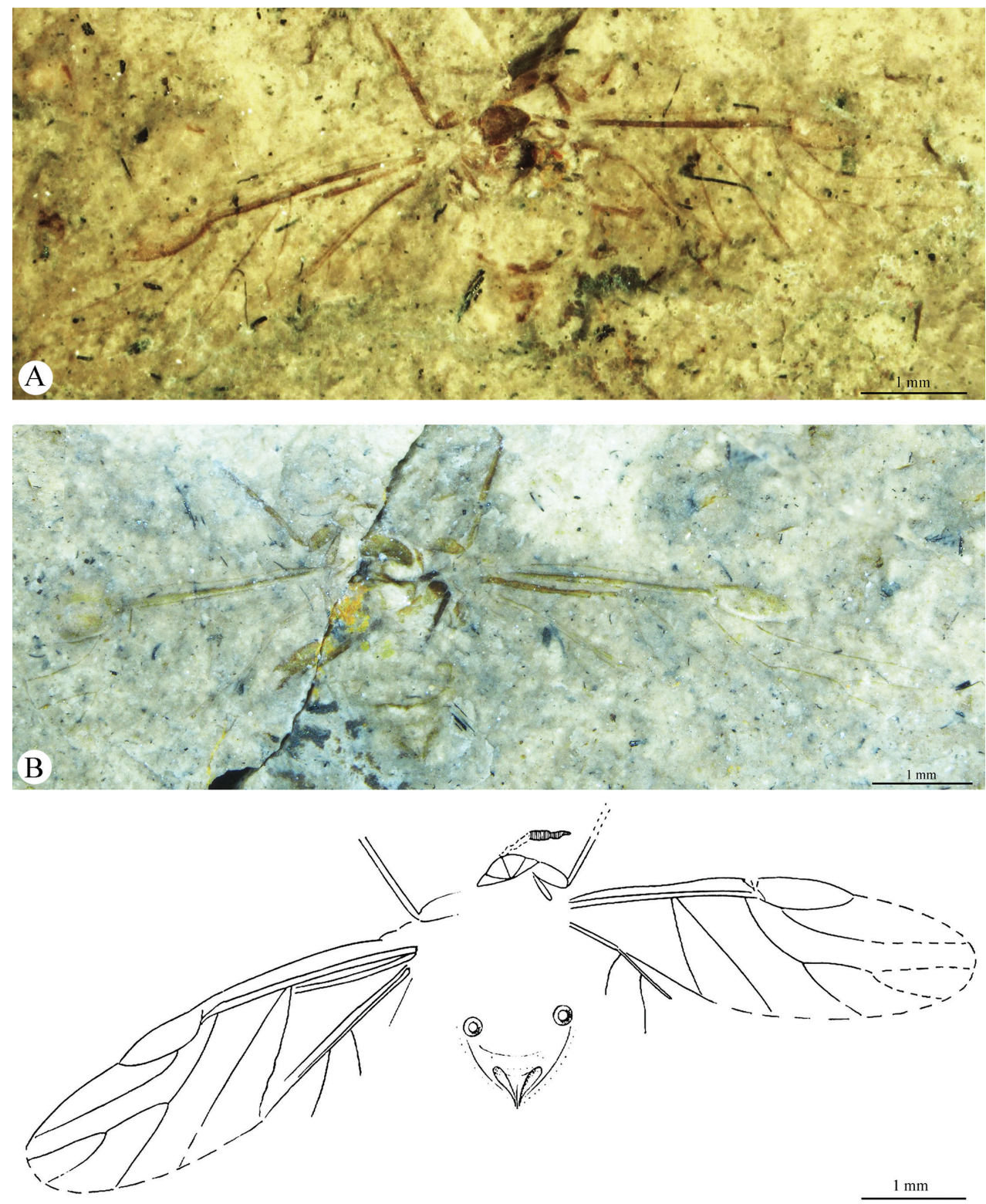

C

Figure I. Oviparosiphum jakovlevi Shaposhnikov, 1979; PIN 3559/51, holotype. A body, ventral view B body, dorsal view C original reconstruction (after Shaposhnikov 1979).

Etymology. The name is a combination of the Greek word archaios (meaning 'ancient') and the genus Oviparosiphum.

Gender. Neuter. 


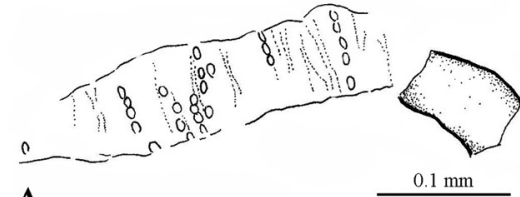

A
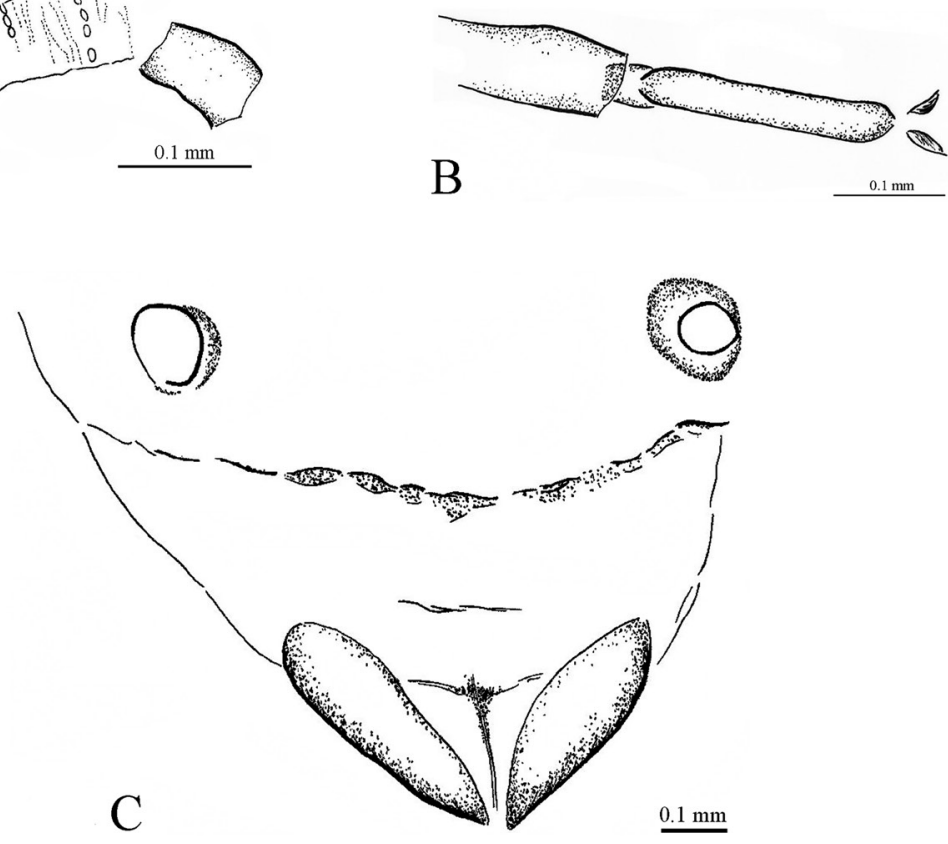

$\mathrm{D}$

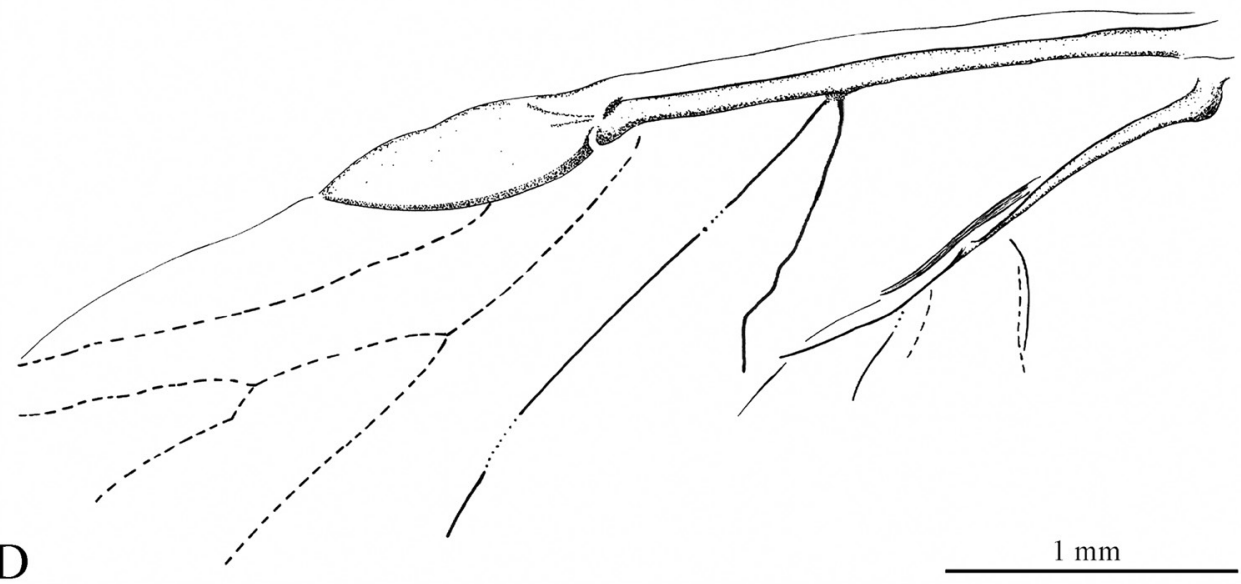

Figure 2. Oviparosiphum jakovlevi Shaposhnikov, 1979; PIN 3559/51, holotype. A fragment of right antenna with secondary rhinaria, dorsal view $\mathbf{B}$ middle tarsus $\mathbf{C}$ apical part of abdomen $\mathbf{D}$ reconstruction of fore wing.

Archeoviparosiphum baissense (Shaposhnikov \& Wegierek, 1989), comb. n.

Figs 5, 6

Holotype. 4210/2623 \pm , Paleontological Institute, Russian Academy of Sciences, Moscow; Baissa locality (Russia); Early Cretaceous; alate female 

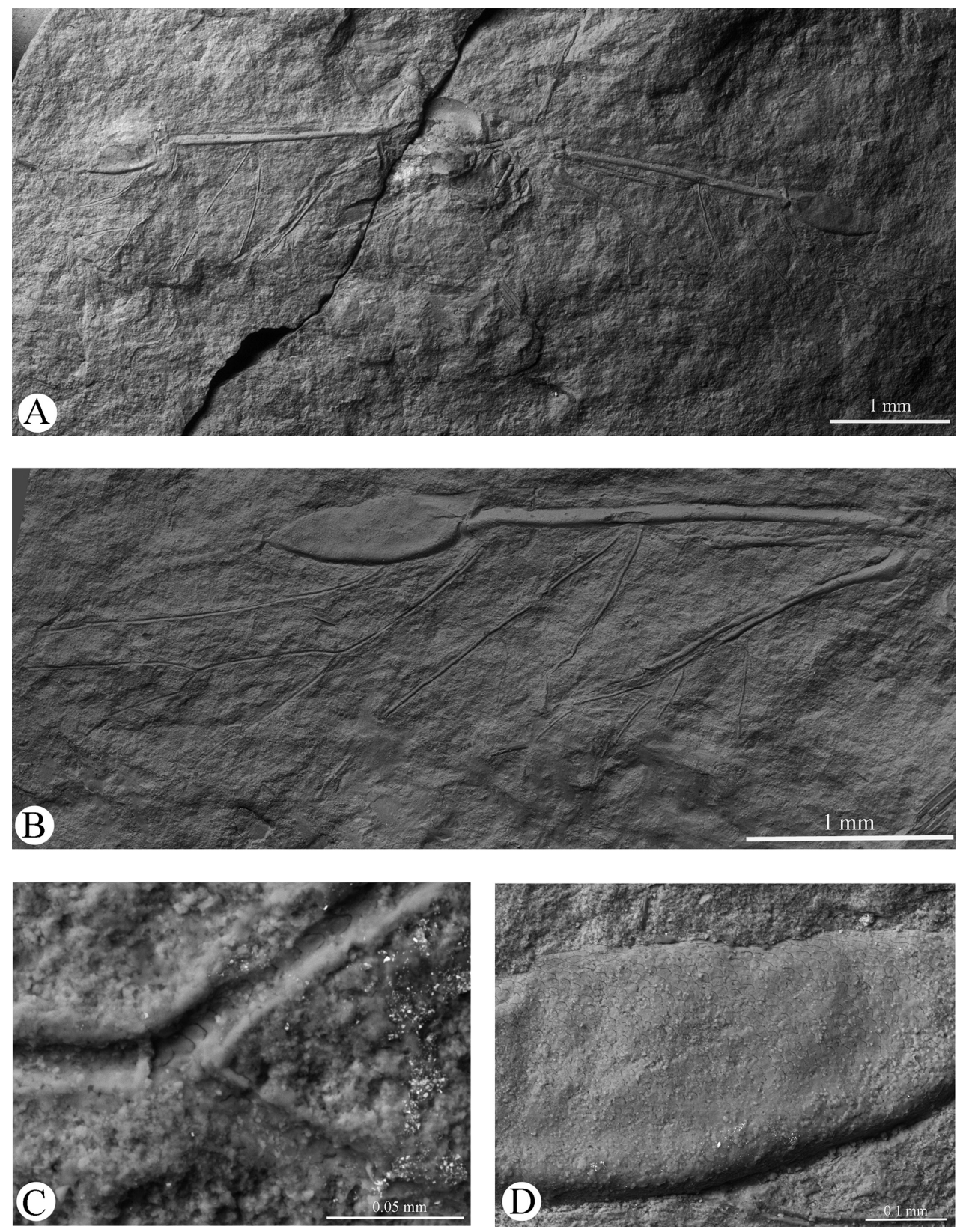

Figure 3. Oviparosiphum jakovlevi Shaposhnikov, 1979; PIN 3559/51, holotype, scanning electron micrographs. A body, dorsal view $\mathbf{B}$ fore wing $\mathbf{C}$ scaly surface of veins $\mathbf{D}$ scaly surface of pterostigma.

Paratypes. 3064/2107; 3064/2108(2273); 3064/2161(2164); 3064/2165; 3064/2166; 3064/2171(5138); 3064/2181; 3064/2184; 3064/2193(2210);

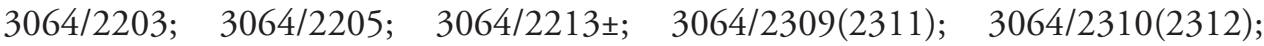



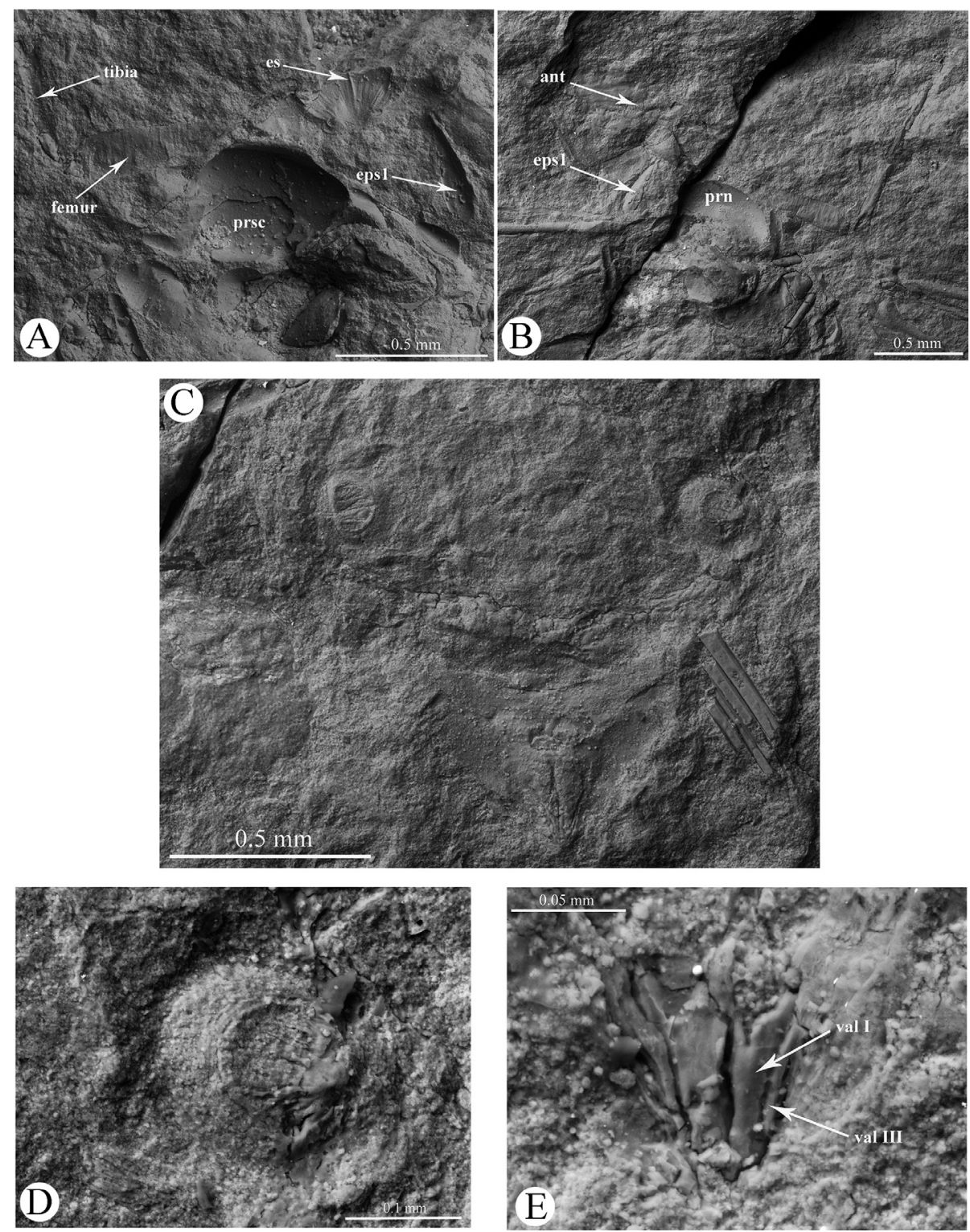

Figure 4. Oviparosiphum jakovlevi Shaposhnikov, 1979; PIN 3559/51, holotype, scanning electron micrographs. A head and thorax, ventral view $\mathbf{B}$ head and thorax, dorsal view $\mathbf{C}$ apical part of abdomen D siphunculi; E. ovipositor. ant - antenna, eps 1 - proepisternum, es - epicranial suture, prn - pronotum, prsc - praescutum, val - valvae.

3064/2313(4846); 3064/2314; 3064/2315(2316); 3064/3978; 3064/4765; $3064 / 4775 ; 3064 / 4816 ; 3064 / 4911 ; 3064 / 4915 ; 3064 / 4916(4922) ; 3064 / 4970$; $3064 / 4975 ; \quad 3064 / 5031 ; 3064 / 5110 ; 4210 / 2521 \pm ; 4210 / 2624 \pm ; \quad 4210 / 2625$; $4210 / 2771 ; 4210 / 2801 \pm ; 4210 / 2802 ; 4210 / 2803$ 

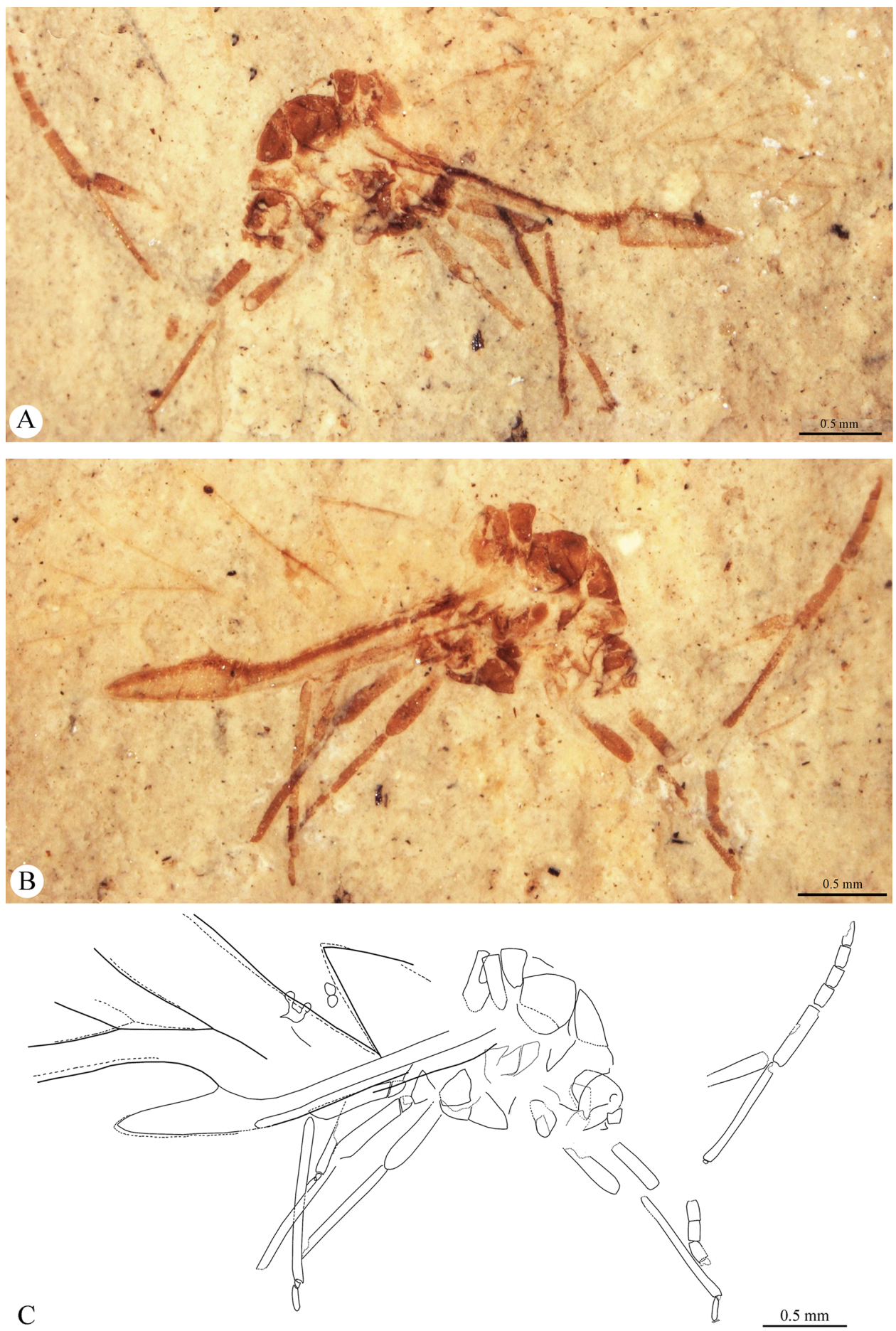

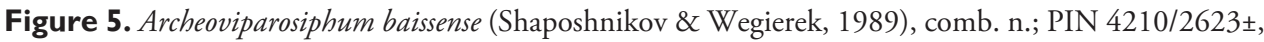
holotype. A, B body, lateral views $\mathbf{C}$ reconstruction of body. 


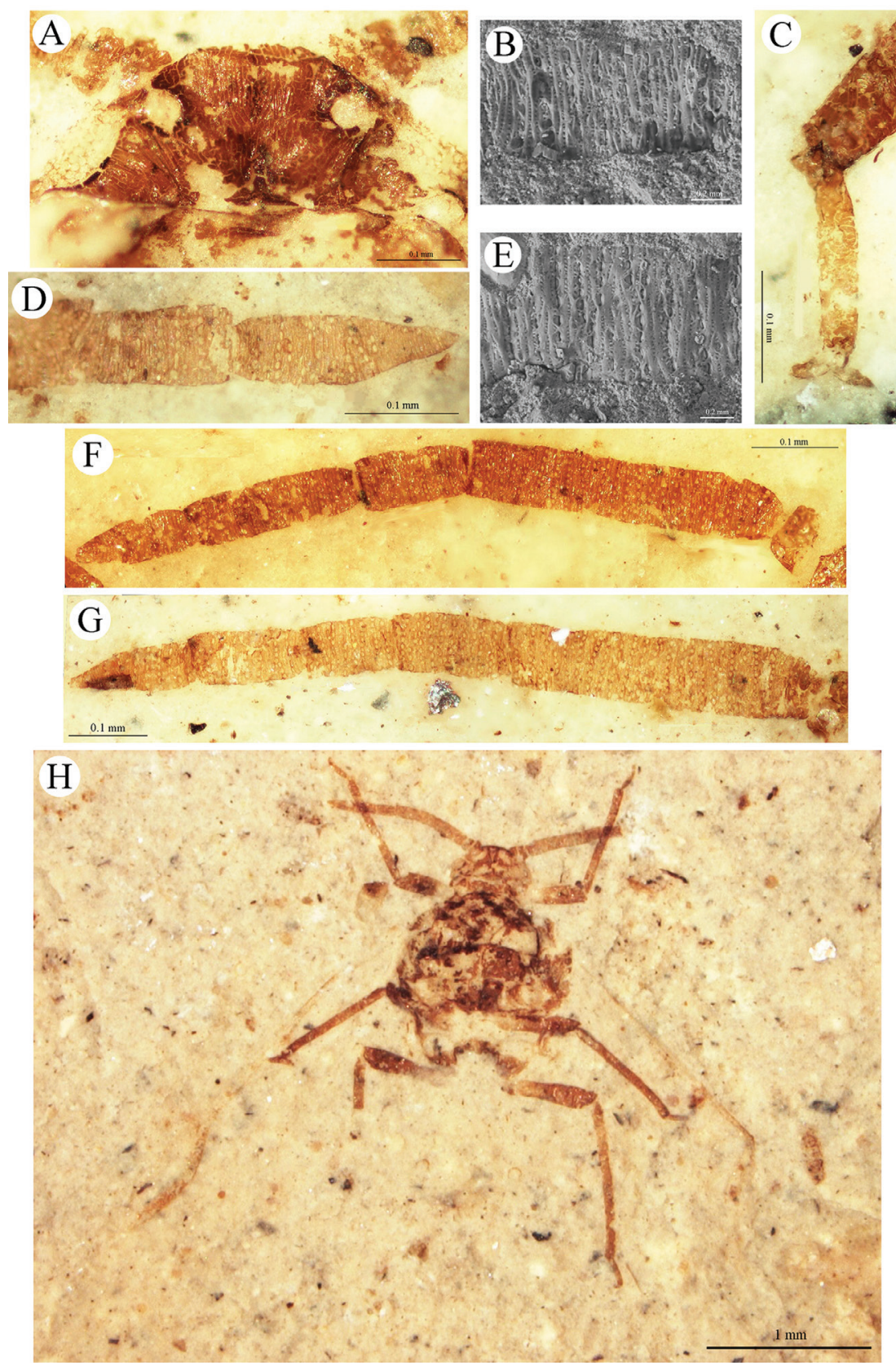

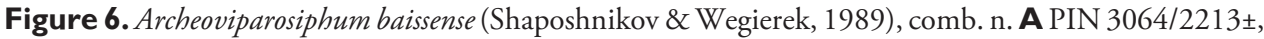
paratype, head, dorsal view B PIN 3064/2284, additional material, fragment of antennal segment V with secondary rhinaria, scanning electron micrograph C PIN 3064/2310(2312), paratype, hind tarsus D PIN 3064/2203, paratype, antennal segment VI and VII with secondary rhinaria E PIN 3064/2284, additional material, fragment of antennal segment III with secondary rhinaria, scanning electron micrograph F PIN 3064/2108(2273), paratype, right antenna G PIN 3064/2310(2312), paratype, left antenna H PIN 3064/2213 \pm , paratype, body, ventral view. 
Additional material. 1989/1072; 3064/2160; 3064/2173(4751); 3064/2225; 3064/2276; 3064/2278; 3064/2284; 3064/4825; 3064/4870; 3064/4990;

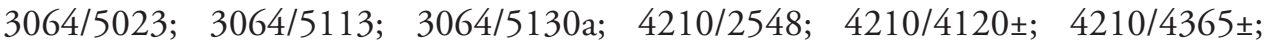
$4210 / 4629 \pm ; 4210 / 5553 \pm ; 4210 / 5588 \pm ; 4210 / 5590 \pm ; 4210 / 5618 \pm ; 4210 / 5630 \pm ;$ 4210/5654; 4210/5659; 4210/5661; 4210/5665; 4210/5669; 4210/5674; 4210/5675;

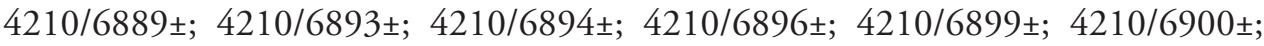
4210/6908; 4210/6911; 4210/6912a; 4210/6915; 4210/7577a \pm ; 4210/7577b \pm ;

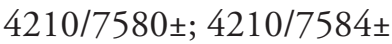

Emended diagnosis. Bases of cubital veins leaving the main vein at the same point.

Description. Body (1.9-2.7) thick (Figs 5A-C, 6H). Anterior margin of head (Fig. 6A) straight. Length of the head (0.19-0.25); width (0.35-0.40). Epicranial suture present, sometimes not clearly visible. Lateral sutures present. On head, additional narrow oblique slats running from front and lateral edges to the posterior part of the head. Distance between ocelli 0.18-0.20. Antennae (0.94-1.40) (Figs 6F, $\mathrm{G})$ half of body length, and longer or equal to hind tibiae length. Segments I 0.050.06 and II $0.04-0.06$ in length. Segment III (0.34-0.42) shorter than the cumulative length of subsequent segments; about 3-4 times longer than wide. Segment IV (0.11-0.14) as long as wide, equal to segment V and VI. Segment VII (0.15-0.18) slightly longer than the previous segment, about twice as long as wide, narrowed in the apical part. Secondary rhinaria arranged in dense, transverse rows (Figs 6B, $\mathrm{D}, \mathrm{E})$, on segment III in 24-30 rows; segments IV-VI in 7-10 rows; segment VII in 5-8 rows. 8-11 secondary rhinaria in one row on segment III. Rostrum relatively long, reaching to the hind coxae. Length of mesoscutellum $0.13-0.15$; width $0.39-0.45$. Length of mesothoracic sternite $0.41-0.46$; width $0.68-0.72$. Length of fore femur 0.34; fore tibia $0.61-0.71$; segment I of fore tarsus 0.03 ; segment II $0.13-0.14$. Length of middle femur $0.39-0.49$; middle tibia $0.68-0.78$; segment I of middle tarsus 0.03 ; segment II $0.15-0.17$. Length of hind coxa $0.15-0.16$; hind trochanter 0.10; hind femur 0.48-0.53; hind tibia 0.89-1.28; segment I of hind tarsus 0.04 (Fig. 6C); segment II 0.17-0.19. Hind tibiae about half the body length. Fore wing (3.10-3.60) longer than body length. Distance from base of wing to end of pterostigma 2.50-2.70. Vein $\mathrm{CuA}_{1}$ about twice as long as $\mathrm{CuA}_{2}$. Vein $\mathrm{M}$ three branched, its base directed to base of pterostigma, not connected with main vein. $M$ furcates to $M_{1+2}$ and $M_{3+4}$ behind Rs base. Common stem of vein $M$ longer than $M_{1+2}$. Vein Rs slightly curved, leaving proximal part of the pterostigma and running far away from it. Pterostigma pointed, long and narrow; 4 times longer than wide. Hind wing (2.70) with two cubital veins. Apical part of abdomen slightly sclerotized. Diameter of siphunculus $0.07-0.08$.

\section{Discussion}

The first species of the genus Oviparosiphum, O. jakovlevi was described in 1979 by Shaposhnikov and assigned to a new family Oviparosiphidae. The diagnostic features 
were the following: antennae with annular secondary rhinaria, siphunculi in the form of truncated cones with a height less than the diameter of the wide aperture, and a large conical ovipositor, most likely composed of four valvae (Shaposhnikov 1979). New techniques made a detailed study possible, confirming the presence of these features and allowing to redescribe the type species of the genus Oviparosiphum. Additionally, analysis of the antennal morphology showed that the secondary rhinaria of Oviparosiphum jakovlevi are slightly ellipsoidal and occur in dense, transverse rows. The second species assigned to this genus was O. baissense from the Baissa deposit (Lower Cretaceous, Russia), described on the basis of a single imprint (Shaposhnikov and Wegierek 1989). The large number of specimens available for the present study permitted a very accurate redescription of the species. The presence of pore-shaped siphunculi has been clearly demonstrated, in contrast to the original description, which highlighted the short cone-shaped siphunculi. The characteristics that distinguish these two species of the genus Oviparosiphum from other genera in the family are similar length of both cubital veins and vein Rs leaving proximal part of the pterostigma. These features remain valid but more attention is paid to the abdomen structure. Only one other genus - Khotonaphis - has clearly truncate conical siphunculi, but its ovipositor is not as well developed as in Oviparosiphum jakovlevi (Shaposhnikov and Wegierek 1989). The species Oviparosiphum latum, described from the Early Cretaceous of China, is more problematic because vein Rs leaves the distal part of the pterostigma, and the fact that the exact structure of the secondary rhinaria is unknown (Hong and Wang 1990). However, the drawings suggest that the siphunculi are pore-shaped, which enables it to be reclassified as a member of the new genus.

In the original description of Paroviparosiphum syn. n. and Mesoviparosiphum syn. n. the authors indicated 5-segmented antennae, annular secondary rhinaria and poreshaped siphunculi as being diagnostic features of both genera (Zhang et al. 1989). However, on the basis of drawings, it could be stated that the antennae are 7-segmented, typical of the Oviparosiphidae, and that the secondary rhinaria are most likely ellipsoidal. Nevertheless the siphunculi seem to be pore-shaped, which makes it possible to include these genera also in Archeoviparosiphum.

The composition of the new genus is thus as follows:

Archeoviparosiphum baissense (Shaposhnikov \& Wegierek, 1989), comb. n.

Oviparosiphum baissensis Shaposhnikov \& Wegierek, 1989: 49 (original combination)

Archeoviparosiphum camptotropum (Zhang, Zhang, Hou \& Ma, 1989), comb. $\mathrm{n}$. Paroviparosiphum camptotropum Zhang, Zhang, Hou \& Ma, 1989: 31 (original combination)

Oviparosiphum camptotropum (Zhang, Zhang, Hou \& Ma, 1989) (synonym by Heie and Wegierek 2011: 49)

Archeoviparosiphum latum (Hong \& Wang, 1990), comb. n.

Oviparosiphum latum Hong \& Wang, 1990: 80 (original combination) 
Archeoviparosiphum malacum (Zhang, Zhang, Hou \& Ma, 1989), comb. n. Mesoviparosiphum malacum Zhang, Zhang, Hou \& Ma, 1989: 33 (original combination) Oviparosiphum malacum (Zhang, Zhang, Hou \& Ma, 1989) (synonym by Heie and Wegierek 2011: 49)

Archeoviparosiphum opimum (Zhang, Zhang, Hou \& Ma, 1989), comb. n.

Paroviparosiphum opimum Zhang, Zhang, Hou \& Ma, 1989 : 29 (original combination) Oviparosiphum opimum (Zhang, Zhang, Hou \& Ma, 1989) (synonym by Heie and Wegierek 2011: 49)

Archeoviparosiphum tuanwangense (Zhang, Zhang, Hou \& Ma, 1989), comb. n. Mesoviparosiphum tuanwangense Zhang, Zhang, Hou \& Ma, 1989: 32 (original combination)

Oviparosiphum tuanwangense (Zhang, Zhang, Hou \& Ma, 1989) (synonym by Heie and Wegierek 2011: 49)

\section{Conclusion}

Previously the genus Oviparosiphum consisted of seven species. It is now limited to a single species, O.jakovlevi, with clearly truncate conical siphunculi and a well-developed ovipositor. The other species have been transferred to a new genus Archeoviparosiphum gen. n.; all these species have pore-shaped siphunculi and a rudimentary ovipositor.

\section{Acknowledgements}

We wish to thank Dr. Dimitrij E. Shcherbakov and Dr. Roman Rakitov from the Palaeontological Institute, Russian Academy of Sciences, Moscow for allowing us to use the specimen and for their help with the SEM photographs. We also want to thank the reviewers for comments that greatly improved the manuscript. We are grateful to Marzena Zmarzły (Department of Zoology, University of Silesia) for the technical assistance, and Peter Senn for kindly checking the English language of the manuscript.

\section{References}

Ansorge J (1996) Insekten aus dem Oberen Lias von Grimmen (Vorpommern, Norddeutschland). Neue Paläontologische Abhandlungen 2: 132.

Heie OE, Wegierek P (2011) A list of fossil aphids (Hemiptera, Sternorrhyncha, Aphidomorpha). Monographs of the Upper Silesian Museum, 82 pp.

Hong YC, Wang WL (1990) Fossil insects from the Laiyang basin, Shandong province. In: Regional Geological Surveying Team, Shandong Bureau of Geology and Mineral Resources 
(Eds) The stratigraphy and palaeontology of Laiyang Basin, Shandong province. Geological Publishing House, Beijing, 44-189. [in Chinese with English summary]

Kania I, Wegierek P (2008) Palaeoaphididae (Hemiptera, Sternorrhyncha) from Lower Cretaceous Baissa deposits. Morphology and classification. Instytut Systematyki i Ewolucji Zwierząt Polskiej Akademii Nauk, Kraków, 133 pp.

Ponomarenko AG (2013) Review of the locations of fossil insects in Mongolia. Palaeoentomology in Russia. Arthropod Lab, Paleontological Institute, Moscow. http://palaeoentomolog.ru/Collections/mong_loc.html [25 November 2013]

Rasnitsyn AP (2002) Special Features of the Study of Fossil Insects. In: Rasnitsyn AP, Quicke DLJ (Eds) History Of Insects. Kluwer Academic Publishers, Dordrecht, 8-12. doi: 10.1007/0-306-47577-4

Rasnitsyn AP, Jarzembowski EA, Ross AJ (1998) Wasps (Insecta: Vespida=Hymenoptera) from the Purbeck and Wealden (Lower Cretaceous) of southern England and their biostratigraphical and paleoenvironmental significance. Cretaceous Research 19(3-4): 329-391. doi: 10.1006/cres.1997.0114

Rasnitsyn AP, Zherikhin VV (2002) Impression fossils. In: Rasnitsyn AP, Quicke DLJ (Eds) History Of Insects. Kluwer Academic Publishers, Dordrecht, 437-444. doi: 10.1007/0306-47577-4_4

Shaposhnikov GK (1979) Late Jurassic and Early Cretaceous aphids. Paleontological Journal 13: 449-461. [in Russian]

Shaposhnikov GCh, Wegierek P (1989) New aphids of the late Mesosoic (Oviparosiphidae, Homoptera). Paleontological Journal 3: 42-50. [in Russian]

Zhang JF, Zhang S, Hou F, Ma G (1989) Late Jurassic aphids (Homoptera, Insecta) from Shandong Province, China. Geology of Shandong 5: 28-46. [in Chinese with English summary]

Zherikhin VV, Mostovski MB, Vrsansky P, Blagoderov VA, Lukashevich ED (1999) The unique Lower Cretaceous locality Baissa and other contemporaneous fossil insect sites in North and West Transbaikalia. Proceedings of the First International Palaeoentomological Conference, Moscow, 1998, 185-191. 